\title{
Glanzmann Thrombasthenia
}

National Cancer Institute

\section{Source}

National Cancer Institute. Glanzmann Thrombasthenia. NCI Thesaurus. Code C61249.

A rare, autosomal recessive inherited and less frequently acquired platelet disorder. It is characterized by deficient or dysfunctional glycoprotein IIb/IIIa complex. It leads to defective platelet aggregation, resulting in bleeding. 